BMJ Open

Respiratory

Research

\title{
Shortened Lung Clearance Index is a repeatable and sensitive test in children and adults with cystic fibrosis
}

\author{
David Hannon, ${ }^{1}$ Judy M Bradley, ${ }^{2}$ Ian Bradbury, ${ }^{2}$ Nicholas Bell, ${ }^{3}$ J Stuart Elborn, ${ }^{1}$ \\ Katherine O'Neill ${ }^{1}$
}

To cite: Hannon D,

Bradley JM, Bradbury I, et al. Shortened Lung Clearance Index is a repeatable and sensitive test in children and adults with cystic fibrosis. BMJ Open Resp Res 2014;1: e000031. doi:10.1136/ bmjresp-2014-000031

\section{- Additional material is} available. To view please visit the journal (http://dx.doi.org/ 10.1136/bmjresp-2014000031)

JSE and KO are Joint senior authors.

Received 12 March 2014 Revised 27 June 2014 Accepted 30 June 2014

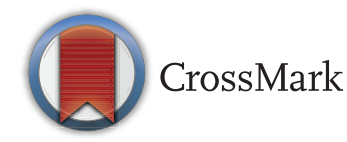

${ }^{1}$ Centre for Infection and Immunity, School of Medicine, Dentistry and Biomedical Sciences, Queen's University Belfast, Belfast, UK ${ }^{2}$ Centre for Health and Rehabilitation Technologies (CHART), University of Ulster, Belfast, UK

${ }^{3}$ Respiratory Medicine Department, Bristol Adult Cystic Fibrosis Centre, Bristol Royal Infirmary, University Hospitals Bristol, Bristol, UK

Correspondence to Professor J Stuart Elborn; s.elborn@qub.ac.uk

\section{ABSTRACT}

Background: Lung clearance index ( $\mathrm{LCl}$ ) derived from sulfur hexafluoride $\left(\mathrm{SF}_{6}\right)$ multiple breath washout (MBW) is a sensitive measure of lung disease in people with cystic fibrosis (CF). However, it can be time-consuming, limiting its use clinically.

Aim: To compare the repeatability, sensitivity and test duration of $\mathrm{LCl}$ derived from washout to $1 / 30$ th $\left(\mathrm{LCl}_{1 / 30}\right)$, 1/20th $\left(\mathrm{LCl}_{1 / 20}\right)$ and 1/10th $\left(\mathrm{LCl}_{1 / 10}\right)$ to 'standard' $\mathrm{LCl}$ derived from washout to $1 / 40$ th initial concentration $\left(\mathrm{LCl}_{1 / 40}\right)$.

Methods: Triplicate MBW test results from 30 clinically stable people with CF and 30 healthy controls were analysed retrospectively. MBW tests were performed using $0.2 \% \mathrm{SF}_{6}$ and a modified Innocor device. All LCl end points were calculated using SimpleWashout software. Repeatability was assessed using coefficient of variation (CV\%). The proportion of people with CF with and without abnormal $\mathrm{LCl}$ and forced expiratory volume in $1 \mathrm{~s}\left(\mathrm{FEV}_{1}\right) \%$ predicted was compared. Receiver operating characteristic (ROC) curve statistics were calculated. Test duration of all $\mathrm{LCl}$ end points was compared using paired t tests.

Results: In people with CF, $\mathrm{LCl}_{1 / 40} \mathrm{CV} \%(\mathrm{p}=0.16), \mathrm{LCl}_{1 /}$ ${ }_{30} \mathrm{CV} \%,(p=0.53), \mathrm{LCl}_{1 / 20} \mathrm{CV} \%(\mathrm{p}=0.14)$ and $\mathrm{LCl} \mathrm{1}_{1 / 10} \mathrm{CV}$ $\%(p=0.25)$ was not significantly different to controls.

The sensitivity of $\mathrm{LCl}_{1 / 40}, \mathrm{LCl}_{1 / 30}$ and $\mathrm{LCl}_{1 / 20}$ to the presence of $\mathrm{CF}$ was equal $(67 \%)$. The sensitivity of $\mathrm{LCl}_{1 /}$ ${ }_{10}$ and $\mathrm{FEV}_{1} \%$ predicted was lower ( $53 \%$ and $47 \%$ respectively). Area under the ROC curve $(95 \% \mathrm{Cl})$ for $\mathrm{LCl}_{1 / 40}, \mathrm{LCl}_{1 / 30}, \mathrm{LCl}_{1 / 20}, \mathrm{LCl}_{1 / 10}$ and $\mathrm{FEV}_{1} \%$ predicted was 0.89 ( 0.80 to 0.97 ), 0.87 (0.77 to 0.96 ), 0.87 (0.78 to $0.96), 0.83$ (0.72 to 0.94 ) and 0.73 (0.60 to 0.86 ), respectively. Test duration of $\mathrm{LCl}_{1 / 30}, \mathrm{LCl}_{1 / 20}$ and $\mathrm{LCl}_{1 / 10}$ was significantly shorter compared with the test duration of $\mathrm{LCl}_{1 / 40}$ in people with $\mathrm{CF}(\mathrm{p}<0.0001)$ equating to a $5 \%, 9 \%$ and $15 \%$ time saving, respectively.

Conclusions: In this study, $\mathrm{LCl}_{1 / 20}$ was a repeatable and sensitive measure with equal diagnostic performance to $\mathrm{LCl}_{1 / 40}$. $\mathrm{LCl}_{1 / 20}$ was shorter, potentially offering a more feasible research and clinical measure.

\section{INTRODUCTION}

Lung Clearance Index (LCI) derived from multiple breath washout (MBW) is a sensitive

\section{KEY MESSAGES}

Lung Clearance Index (LCI) can be timeconsuming, limiting its use clinically.

- Investigation of the flexibility of current multiple breath washout test end points is an important area for future research.

- $\mathrm{LCl}_{1 / 20}$ is a repeatable and sensitive test that is shorter than $\mathrm{LCl}_{1 / 40}$, potentially offering a more feasible research and clinical measure.

measure of ventilation inhomogeneity ${ }^{12}$ and a robust surrogate outcome measure of the severity of lung disease in cystic fibrosis $(\mathrm{CF})^{3}$ which has begun to be incorporated into clinical trials. ${ }^{4} 5$ It also shows promise as a sensitive outcome measure in idiopathic bronchiectasis $^{6}$ and asthma. ${ }^{7}$ A drawback of the test is that it can be time-consuming, especially in patients with advanced disease, limiting its feasibility within the clinical environment. By convention a MBW test involves performing a minimum of three inert tracer gas washout runs, ending the washout when end-tidal tracer gas concentration falls below $1 / 40$ th of the initial concentration. ${ }^{8}$ The end point of $1 / 40$ th is based on historic studies and has not been systematically validated. ${ }^{89}$ The European Respiratory Society/American Thoracic Society (ERS/ATS) consensus statement highlights investigation of the flexibility of current MBW test end points as an important area for future research, which could potentially improve the utility of this test. ${ }^{8}$ Assessment of the clinimetric properties of shortened LCI in CF using nitrogen $\left(\mathrm{N}_{2}\right)$ MBW testing $(100 \%$ as the inert gas), have reported good diagnostic performance in children with mild disease, offering a measure of ventilation inhomogeneity which may be more practical in the clinical setting. ${ }^{10}$ However, there are no studies to assess the performance of shortened LCI using sulfur hexafluoride $\left(\mathrm{SF}_{6}\right)$ MBW 
(another common MBW method), or studies of shortened LCI in adult patients with more moderate to advanced disease. Differences in gas diffusion and molecular mass of the inert gases used mean that results of the two types of test are not comparable. ${ }^{11}$ Study of the sensitivity of shortened MBW tests using $\mathrm{SF}_{6}$ could be useful in improving the clinical utility of these tests.

In this study we aimed to assess and compare the repeatability, sensitivity, specificity and test duration of LCI derived from washout to $1 / 30$ th $\left(\mathrm{LCI}_{1 / 30}\right), 1 / 20$ th $\left(\mathrm{LCI}_{1 / 20}\right)$ and $1 / 10$ th of the initial concentration $\left(\mathrm{LCI}_{1 / 10}\right)$ to 'standard' LCI derived from washout to $1 / 40$ th initial concentration $\left(\mathrm{LCI}_{1 / 40}\right)$, using $0.2 \% \mathrm{SF}_{6}$ as the tracer gas, in school age-adolescent children and adults with CF and healthy controls.

\section{METHODS}

\section{Subject recruitment}

Cross-sectional data from 30 people with $\mathrm{CF}$ ( $\mathrm{n}=15$ aged $6-17$ years old; $n=15$ aged $\geq 18$ years old) and 30 healthy control participants $(\mathrm{n}=15$ aged $6-17$ years old; $\mathrm{n}=15$ aged $\geq 18$ years old) with three valid and repeatable MBW tests were analysed. Thirty anonymised CF and 30 healthy control data sets, as consecutively listed in a database of results collected in a large prospective project investigating the clinimetric and clinical relevance of LCI in CF were used. People with CF were recruited at a routine outpatient visit to the Northern Ireland paediatric and adult CF centres at Belfast Health and Social Care Trust (BHSCT), when clinically stable (no pulmonary exacerbation requiring intravenous antibiotics in the previous 4 weeks), between October 2010 and June 2013. Control participants were recruited by means of email circulation among people employed in Queen's University Belfast (QUB) and BHSCT between September 2011 and August 2012. All adult participants provided written informed consent. All child participants provided child or young person assent and parental consent.

\section{MBW testing}

The MBW test to measure LCI was carried out using a modified Innocor device and $0.2 \% \mathrm{SF}_{6}$ using the opencircuit technique in accordance with the standard operating procedure developed by the UK CF Gene Therapy Consortium (UKCFGTC; see online supplementary file 1) as described and validated by Horsley $e t a l^{2}$ and used in a recent CF clinical trial and observational study. ${ }^{4}{ }^{12}$ Participants breathed through a mouthpiece at tidal volumes, while in a seated position and wearing a nose clip. Participants breathed $0.2 \% \mathrm{SF}_{6}$ in air via a flowpast circuit until washin was complete, at which point the flowpast was disconnected and the participant breathed room air until the end tidal expired $\mathrm{SF}_{6}$ concentration fell below $1 / 40$ th of the initial concentration before disconnection. Three washouts were performed for each participant. Analysis of MBW data was performed using the SimpleWashout programme developed by $\mathrm{Dr}$ Nicholas Bell (UKCFGTC) and used with his permission (see online supplementary file 1). For each washout, four values for functional residual capacity (FRC) and LCI were calculated:

- $\mathrm{FRC}_{1 / 40}$ and $\mathrm{LCI}_{1 / 40}$ were derived from washout data from flowpast disconnection until the first breath with end tidal $\mathrm{SF}_{6}$ concentration below $1 / 40$ th $(\leq 0.005 \%)$ of the starting $\mathrm{SF}_{6}$ concentration $(0.2 \%)$.

- $\mathrm{FRC}_{1 / 30}$ and $\mathrm{LCI}_{1 / 30}$ were derived from washout data from flowpast disconnection until the first breath with end tidal $\mathrm{SF}_{6}$ concentration below 1/30th $(\leq 0.007 \%)$ of the starting $\mathrm{SF}_{6}$ concentration $(0.2 \%)$.

- $\mathrm{FRC}_{1 / 20}$ and $\mathrm{LCI}_{1 / 20}$ were derived from washout data from flowpast disconnection until the first breath with end tidal $\mathrm{SF}_{6}$ concentration below 1/20th $(\leq 0.01 \%)$ of the starting $\mathrm{SF}_{6}$ concentration $(0.2 \%)$.

- $\mathrm{FRC}_{1 / 10}$ and $\mathrm{LCI}_{1 / 10}$ were derived from washout data from flowpast disconnection until the first breath with end tidal $\mathrm{SF}_{6}$ concentration below 1/10th $(\leq 0.02 \%)$ of the starting $\mathrm{SF}_{6}$ concentration $(0.2 \%)$.

Mean LCI and FRC values and test duration (minutes) for each end point were calculated from each of the three washouts in each testing session.

\section{Spirometry}

Spirometry was measured according to American Thoracic Society/European Respiratory Society ATS/ ERS guidelines ${ }^{13}$ using a Microlab (ML3500 MK8) spirometer (CareFusion, Kent, UK). Predicted values were calculated from reference ranges for all ages. ${ }^{14}$

\section{Statistical analysis}

Data were analysed using PASW Statistics (V.18, IBM software, USA) and Prism (V.5.01 GraphPad Software Inc.) packages. CF and control participant characteristics were summarised using descriptive statistics.

Intravisit repeatability of $\mathrm{LCI}_{1 / 40}, \mathrm{LCI}_{1 / 30} \mathrm{LCI}_{1 / 20}$ and $\mathrm{LCI}_{1 / 10}$ was assessed using the coefficient of variation $(\mathrm{CV} \%)$ of all three tests and Bland-Altman plots ${ }^{15}$ comparing tests one and three, for people with $\mathrm{CF}$ and healthy controls. Results between people with $\mathrm{CF}$ and healthy controls were compared using an independent samples t test. Mean LCI and FRC values for each end point from people with $\mathrm{CF}$ or healthy controls were compared using paired samples $\mathrm{t}$ tests. The relationship between mean $\mathrm{LCI}_{1 / 40}$ and mean $\mathrm{LCI}_{1 / 30}, \mathrm{LCI}_{1 / 20}$ and $\mathrm{LCI}_{1 / 10}$ was assessed using scatter plots and the Spearman's rank correlation coefficient. This analysis was also used to assess the relationship between $\mathrm{FEV}_{1} \%$ predicted and all LCI end points. Sensitivity of all LCI end points compared with $\mathrm{FEV}_{1} \%$ predicted was assessed using scatter plots and limits of normal of respective tests calculated from healthy controls (mean $+1.96 \mathrm{SD})$. Sensitivity and specificity were further analysed using receiver operating characteristic (ROC) curves, and by comparing area under the ROC curve $\left(\mathrm{AUC}_{\mathrm{ROC}}\right)$ and $95 \% \mathrm{CI}$ for $\mathrm{LCI}_{1 / 40}, \mathrm{LCI}_{1 / 30}, \mathrm{LCI}_{1 / 20}$, 
$\mathrm{LCI}_{1 / 10}$ and $\mathrm{FEV}_{1} \%$ predicted. Mean test duration (minutes) of $\mathrm{LCI}_{1 / 40}, \mathrm{LCI}_{1 / 30}, \mathrm{LCI}_{1 / 20}$ and $\mathrm{LCI}_{1 / 10}$ was compared using a paired samples t test. As multiple comparisons were being made, a Bonferroni adjustment was incorporated. A $p$ value of $<0.01$ was considered statistically significant.

\section{RESULTS}

$\mathrm{LCI}_{1 / 40}, \mathrm{LCI}_{1 / 30}, \mathrm{LCI}_{1 / 20}, \mathrm{LCI}_{1 / 10}$ and $\mathrm{FEV}_{1} \%$ predicted were significantly different between the $\mathrm{CF}$ and control group. However, there was no difference between the $\mathrm{CF}$ and control group in age, sex, $\mathrm{LCI}_{1 / 40} \mathrm{CV} \%, \mathrm{LCI}_{1 / 30} \mathrm{CV}$ $\%, \mathrm{LCI}_{1 / 20} \mathrm{CV} \%, \mathrm{LCI}_{1 / 10} \mathrm{CV} \%$ or test duration of any LCI end point (table 1).

There was no difference between the $\mathrm{CF}$ and control group in any of the $\mathrm{FRC}$ values $\left(\mathrm{FRC}_{1 / 40}, \mathrm{FRC}_{1 / 30}\right.$, $\mathrm{FRC}_{1 / 20}$ or $\left.\mathrm{FRC}_{1 / 10}\right)$. Within the CF group, as expected, FRC was incrementally lower with each earlier end point. Although $\mathrm{FRC}_{1 / 40}$, and $\mathrm{FRC}_{1 / 30}$ were not significantly different (1.95 vs 1.93, p=0.07) $\quad \mathrm{FRC}_{1 / 40}$ and $\mathrm{FRC}_{1 / 20}(1.95$ vs 1.90, $\mathrm{p}=0.002)$ and $\mathrm{FRC}_{1 / 40}$ and $\mathrm{FRC}_{1 / 10}$ (1.95 vs 1.84 ) were significantly different.

\section{Intravisit repeatability}

$\mathrm{LCI}_{1 / 40} \mathrm{CV} \%, \mathrm{LCI}_{1 / 30} \mathrm{CV} \%, \mathrm{LCI}_{1 / 20} \mathrm{CV} \%$ and $\mathrm{LCI}_{1 / 10}$ $\mathrm{CV} \%$ in people with $\mathrm{CF}$ were not significantly different to values in healthy controls (table 1 ). There was also no significant difference between $\mathrm{LCI}_{1 / 40} \mathrm{CV} \%$ and the $\mathrm{CV}$ $\%$ of any other LCI end point in people with CF. A Bland-Altman $\operatorname{plot}^{15}$ of the mean versus the difference between tests one and three of $\mathrm{LCI}_{1 / 40}, \mathrm{LCI}_{1 / 30}, \mathrm{LCI}_{1 / 20}$ and $\mathrm{LCI}_{1 / 10}$ for people with CF showed no evidence of greater variability in participants with more advanced disease (ie, a higher LCI reading; figure 1A-D).

For $\mathrm{LCI}_{1 / 40}$, the $95 \%$ limits of agreement between the two measurements were -1.70 to 1.33 lung turnovers, compared with -1.33 to $1.07\left(\mathrm{LCI}_{1 / 30}\right),-1.43$ to 0.96 $\left(\mathrm{LCI}_{1 / 20}\right)$ and -0.83 to $0.66\left(\mathrm{LCI}_{1 / 10}\right)$ lung turnovers. Therefore the intravisit repeatability of the $\mathrm{LCI}_{1 / 40}$, $\mathrm{LCI}_{1 / 30}, \mathrm{LCI}_{1 / 20}$ and $\mathrm{LCI}_{1 / 10}$ measurements was $1.5,1.2$, 1.2 and 0.7 lung turnovers respectively.

Relationship between shortened LCI and 'standard' $\mathrm{LCl}_{1 / 40}$ In people with $\mathrm{CF}, \mathrm{LCI}_{1 / 30}(\mathrm{r}=0.98, \mathrm{p}<0.0001), \mathrm{LCI}_{1 / 20}$ $(\mathrm{r}=0.95, \mathrm{p}<0.0001)$ and $\mathrm{LCI}_{1 / 10}(\mathrm{r}=0.88, \mathrm{p}<0.0001)$ correlated significantly with $\mathrm{LCI}_{1 / 40}$ (figure 2 ).

\section{Sensitivity and specificity}

The upper limit of normal for $\mathrm{LCI}_{1 / 40}, \mathrm{LCI}_{1 / 30}, \mathrm{LCI}_{1 / 20}$ and $\mathrm{LCI}_{1 / 10}$ was $7.3,6.7,5.9$ and $4.6 \mathrm{lung}$ turnovers, respectively, (control mean $+1.96 \mathrm{SD}$ ). The lower limit of normal of $80 \%$ for $\mathrm{FEV}_{1} \%$ predicted was used, as this is the level that is historically used in clinical practice.

The sensitivity of $\mathrm{LCI}_{1 / 40}, \mathrm{LCI}_{1 / 30}, \mathrm{LCI}_{1 / 20}$ to differentiate between people with $\mathrm{CF}$ and healthy controls was identical $(67 \%)$. The sensitivity of $\mathrm{LCI}_{1 / 10}$ and $\mathrm{FEV}_{1} \%$ predicted was lower (53\% and $47 \%$, respectively). In people with $\mathrm{CF}, \mathrm{LCI}_{1 / 40}(\mathrm{r}=-0.73, \mathrm{p}<0.0001), \mathrm{LCI}_{1 / 30}$ $(\mathrm{r}=-0.70, \mathrm{p}<0.0001), \mathrm{LCI}_{1 / 20} \quad(\mathrm{r}=-0.69, \mathrm{p}<0.0001)$ and $\mathrm{LCI}_{1 / 10} \quad(\mathrm{r}=-0.62, \mathrm{p}=0.0003)$ correlated significantly with $\mathrm{FEV}_{1} \%$ predicted (figures 3A-D). Using $\mathrm{LCI}_{1 / 40}, 6 / 30$ (20\%) people with CF had an abnormal LCI in the

Table 1 CF and healthy control participant characteristics

\begin{tabular}{|c|c|c|c|}
\hline & People with CF & Healthy controls & p Value (CF vs controls) \\
\hline $\mathrm{N}$ & 30 & 30 & - \\
\hline $\mathrm{M} / \mathrm{F}$ & $14 / 16$ & $16 / 14$ & 0.61 \\
\hline Age (years) & $20.7(11.1)(6-51)$ & $20.8(10.7)(7-44)$ & 0.93 \\
\hline $\mathrm{FEV}_{1}$ (\% predicted) & 79.3 (17.9) (46.0-116.0) & 92.9 (11.3) (68.0-116.0) & 0.009 \\
\hline $\mathrm{FRC}_{1 / 40}(\mathrm{~L})$ & $1.95(0.76)$ & $2.23(1.0)$ & 0.22 \\
\hline $\mathrm{LCl}_{1 / 40}$ (number of turnovers) & $9.0(2.4)$ & $6.4(0.5)$ & $<0.0001$ \\
\hline $\mathrm{LCl}_{1 / 40} \mathrm{CV} \%$ & $5.2(2.8)$ & $4.3(2.0)$ & 0.16 \\
\hline $\mathrm{LCl}_{1 / 40}$ triplicate test duration (min) & $21.8(9.7)(8.0-57.1)$ & $19.4(6.5)(10.1-31.1)$ & 0.26 \\
\hline $\mathrm{FRC}_{1 / 30}(\mathrm{~L})$ & $1.93(0.76)$ & $2.24(1.02)$ & 0.18 \\
\hline $\mathrm{LCl}_{1 / 30}$ (number of turnovers) & $7.7(1.6)$ & $5.9(0.4)$ & $<0.0001$ \\
\hline $\mathrm{LCl}_{1 / 30} \mathrm{CV} \%$ & $4.6(3.2)$ & $4.1(2.8)$ & 0.53 \\
\hline $\mathrm{LCl}_{1 / 30}$ triplicate test duration (min) & $20.9(9.1)(7.3-53.2)$ & $18.9(6.2)(9.9-29.9)$ & 0.34 \\
\hline $\mathrm{FRC}_{1 / 20}(\mathrm{~L})$ & $1.90(0.75)$ & $2.24(1.0)$ & 0.15 \\
\hline $\mathrm{LCl}_{1 / 20}$ (number of turnovers) & $6.6(1.2)$ & $5.2(0.4)$ & $<0.0001$ \\
\hline $\mathrm{LCl}_{1 / 20} \mathrm{CV} \%$ & $5.7(3.4)$ & $4.6(2.3)$ & 0.14 \\
\hline $\mathrm{LCl}_{1 / 20}$ triplicate test duration (min) & $20.0(8.9)(6.7-51.7)$ & $18.35 .9(9.6-28.3)$ & 0.38 \\
\hline $\mathrm{FRC}_{1 / 10}(\mathrm{~L})$ & $1.84(0.73)$ & $2.22(1.00)$ & 0.09 \\
\hline $\mathrm{LCl}_{1 / 10}$ (number of turnovers) & $4.7(0.6)$ & $4.0(0.3)$ & $<0.0001$ \\
\hline $\mathrm{LCl}_{1 / 10} \mathrm{CV} \%$ & $5.4(3.8)$ & $4.3(2.8)$ & 0.25 \\
\hline $\mathrm{LCl}_{1 / 10}$ triplicate test duration (min) & $18.6(8.1)(5.7-46.9)$ & $17.1(5.5)(8.8-26.6)$ & 0.41 \\
\hline
\end{tabular}

All values summarised as mean (SD) \pm (range).

$\mathrm{CF}$, cystic fibrosis; CV, coefficient of variation, $\mathrm{F}$, female; $\mathrm{FEV}_{1}$, forced expiratory volume in $1 \mathrm{~s}$; FRC, functional residual capacity; LCl, Lung Clearance Index; M, male. 
A @

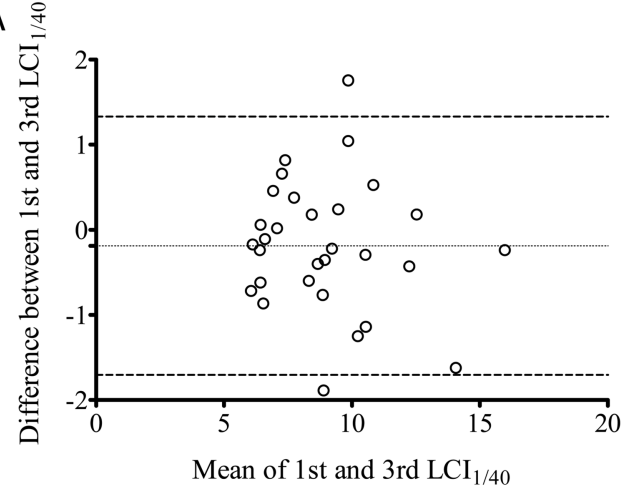

$C \cong$

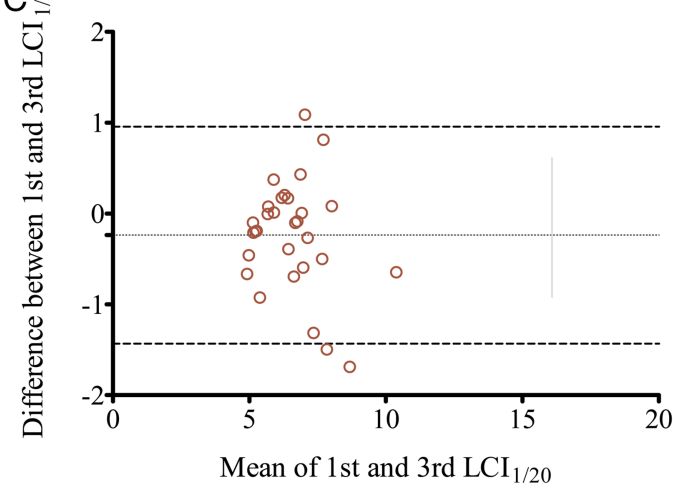

$\mathrm{B}$
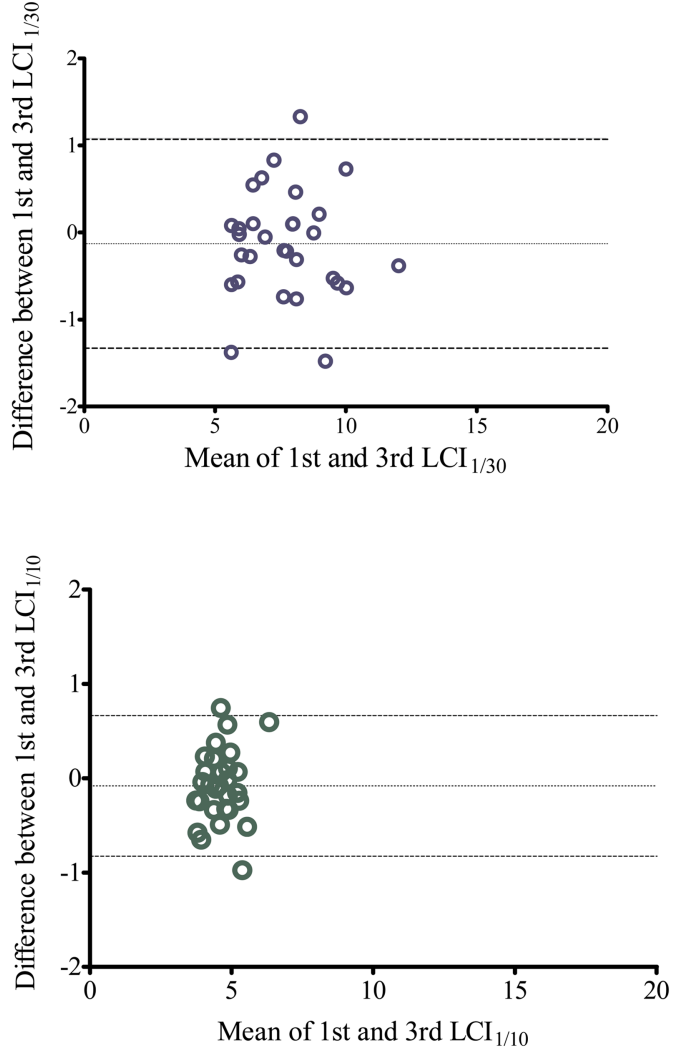

Figure 1 (A) Lung Clearance Index (LCl)1/40; (B) LCl1/30; (C) LCl1/20; (D) LCl1/10 first and third test in people with cystic fibrosis (dotted horizontal lines represent the bias and $95 \%$ limits of agreement).

presence of a normal $\mathrm{FEV}_{1} \%$ predicted (figure $3 \mathrm{~A}$ ). Similarly, using $\mathrm{LCI}_{1 / 30}$ or $\mathrm{LCI}_{1 / 20}, 7 / 30$ (23\%) people with $\mathrm{CF}$ had an abnormal LCI in the presence of a normal $\mathrm{FEV}_{1} \%$ predicted (figure 3B-C). $\mathrm{LCI}_{1 / 10}$ was less sensitive, detecting $5 / 30(17 \%)$ with an abnormal LCI in the presence of a normal $\mathrm{FEV}_{1} \%$ predicted (figure $3 \mathrm{D}$ ).

ROC curve analysis (figure 4) showed that while all LCI values and $\mathrm{FEV}_{1} \%$ predicted had statistically significant levels of sensitivity and specificity in determining people with $\mathrm{CF}$ vs control participants, $\mathrm{LCI}_{1 / 40}, \mathrm{LCI}_{1 / 30}$

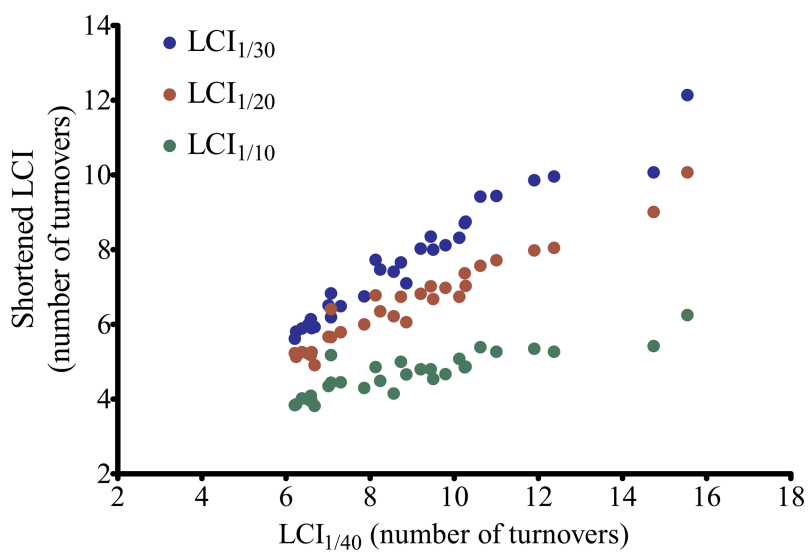

Figure 2 Shortened Lung Clearance Index $(\mathrm{LCl})$ versus standard LCl1/40 in people with cystic fibrosis. and $\mathrm{LCI}_{1 / 20}$ had comparable and higher sensitivity and specificity compared with $\mathrm{LCI}_{1 / 10}$ and $\mathrm{FEV}_{1} \%$ predicted (table 2).

\section{Test duration}

Test duration of $\mathrm{LCI}_{1 / 30}, \mathrm{LCI}_{1 / 20}$ and $\mathrm{LCI}_{1 / 10}$ was significantly shorter compared with washout duration of $\mathrm{LCI}_{1}$ ${ }_{40}$ in people with CF $(p<0.0001)$ and in healthy controls $(\mathrm{p}<0.0001$; table 1$)$. In people with $\mathrm{CF}$, the mean $(95 \%$ CI) time saving per triplicate MBW test was 1 (0.8 to 1.3) minutes or $5 \%$ with $\mathrm{LCI}_{1 / 30}, 1.9$ (1.4 to 2.3) minutes or $9 \%$ with $\mathrm{LCI}_{1 / 30}$ and 3.3 (2.6 to 4.2 ) minutes or $15 \%$ with $\mathrm{LCI}_{1 / 10}$.

\section{DISCUSSION}

This study is the first to show that $\mathrm{SF}_{6} \mathrm{MBW}$ tests can be reliably shortened. Results show that in children and adults with CF, LCI shortened to $1 / 30$ th or $1 / 20$ th $\left(\mathrm{LCI}_{1 / 30}\right.$ or $\left.\mathrm{LCI}_{1 / 20}\right)$ of the initial concentration have comparable intravisit repeatability and sensitivity to 'standard' LCI at $1 / 40$ th of the starting concentration $\left(\mathrm{LCI}_{1 / 40}\right)$ providing additional information to $\mathrm{FEV}_{1} \%$ predicted and offering a time saving. Although repeatable, LGI shortened to $1 / 10$ th of the starting concentration $\left(\mathrm{LCI}_{1 / 10}\right)$ was less sensitive to lung disease, compared with the other LCI end points. It was, however, still more sensitive than $\mathrm{FEV}_{1} \%$ predicted. 

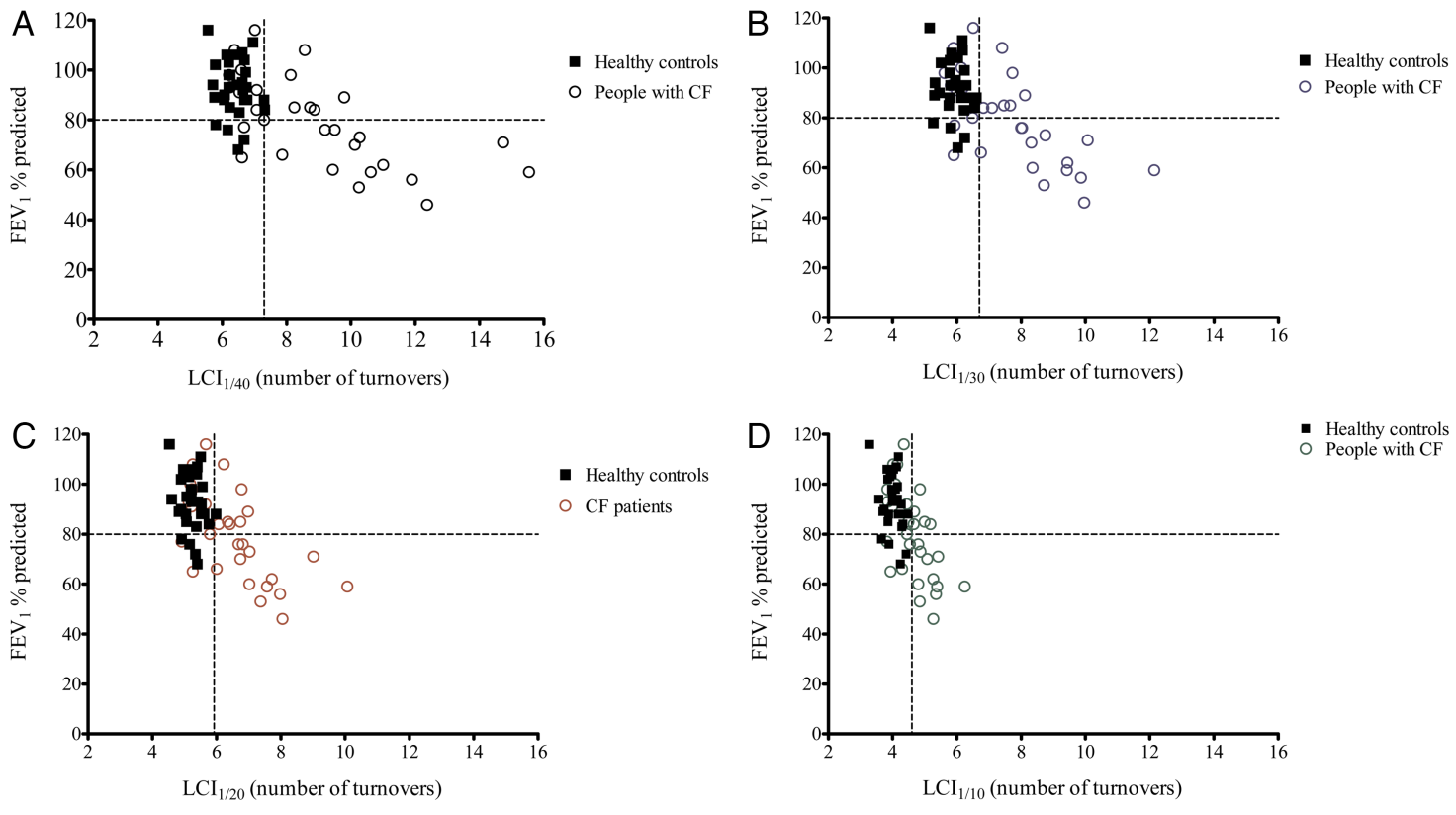

Figure 3 Forced expiratory volume in $1 \mathrm{~s}$ (FEV1)\% predicted versus (A) LCl1/40; (B) LCl1/30; (C) LCl1/20 (D) LCl1/10 (dotted horizontal lines represent the limits of normal for FEV1\% predicted (80\% predicted) and $\mathrm{LCl}(\mathrm{LCl} / 40: 7.3 ; \mathrm{LCl} 1 / 30: 6.7$; LCl1/20:5.9; LCl1/10:4.6)).

The 'standard' end point of $1 / 40$ th is based on historic studies using nitrogen washout $(2.5 \%)$ and has not been systematically validated for $\mathrm{MBW}$ tests using $\mathrm{SF}_{6} .{ }^{8} 9$ This study aimed to assess the performance of earlier arbitrary end points compared with the 'standard' end point in the $\mathrm{SF}_{6}$ washout, in an attempt to improve the clinical utility of the MBW test by reducing test duration. Like $\mathrm{LCI}_{1 / 40}, \mathrm{LCI}_{1 / 30}$ and $\mathrm{LCI}_{1 / 20}$ target the flatter tail of the washout curve, making it unsurprising that similar information can be obtained (see online supplementary file 2). In contrast, when using $\mathrm{LCI}_{1 / 10}$, the end point occurs before the washout curve flattens. This supports the theory that most information is contained in the tail of the washout curve. ${ }^{16}$ Therefore a cut-off before this point may provide less information about lung disease severity, as highlighted by the lower sensitivity of $\mathrm{LCI}_{1 / 10}$ in this study. Yammine $e t a l^{10}$ assessed the repeatability and sensitivity of shortened $\mathrm{N}_{2} \mathrm{MBW}$ to measure LCI, at a number of earlier end points including $1 / 20$ th of the starting concentration and as early as $1 / 5$ th of the
Figure 4 Receiver operating characteristic ROC curve of Lung Clearance Index (LCI)1/40, LCl1/ 30, LCl1/20, LCl1/10 and inverse forced expiratory volume in $1 \mathrm{~s} \%$ predicted: sensitivity and specificity to the presence of cystic fibrosis CF.

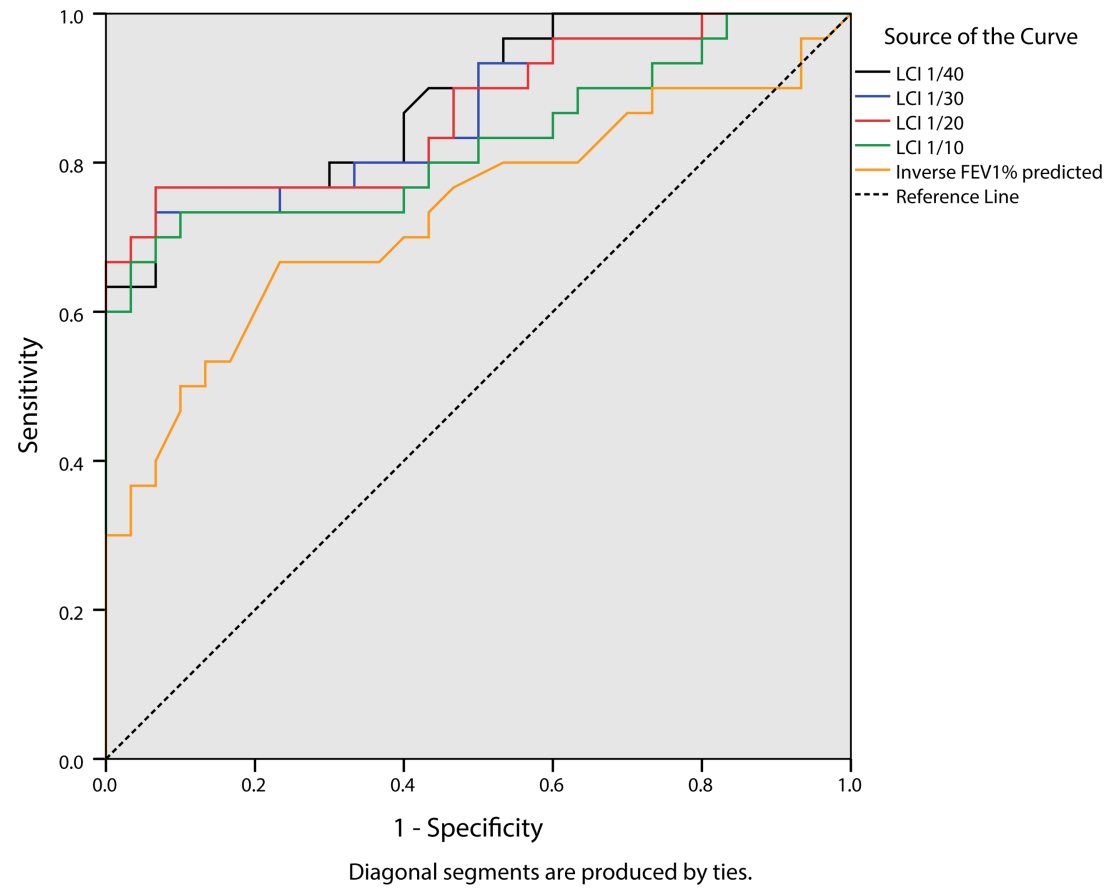


Table $2 \quad \mathrm{AUC}_{\mathrm{ROC}}$ and $95 \% \mathrm{Cl}$ for $\mathrm{LCl}_{1 / 40}, \mathrm{LCl}_{1 / 30}, \mathrm{LCl}_{1 / 20}$ $\mathrm{LCl}_{1 / 10}$ and inverse $\mathrm{FEV}_{1} \%$ predicted (1.0 indicating best performance, 0.5 indicating poor performance)

\begin{tabular}{|c|c|c|c|}
\hline & $\mathrm{AUC}_{\mathrm{ROC}}$ & $95 \% \mathrm{Cl}$ & p Value \\
\hline $\mathrm{LCl}_{1 / 40}$ & 0.89 & 0.80 to 0.97 & $<0.0001$ \\
\hline $\mathrm{LCl}_{1 / 30}$ & 0.87 & 0.77 to 0.96 & $<0.0001$ \\
\hline $\mathrm{LCl}_{1 / 20}$ & 0.87 & 0.78 to 0.96 & $<0.0001$ \\
\hline $\mathrm{LCl}_{1 / 10}$ & 0.83 & 0.72 to 0.94 & $<0.0001$ \\
\hline $\begin{array}{l}\mathrm{FEV}_{1} \% \text { predicted } \\
\text { (inverse) }\end{array}$ & 0.73 & 0.60 to 0.86 & 0.002 \\
\hline
\end{tabular}

AUC, area under the curve; $F E V_{1}$, forced expiratory volume in $1 \mathrm{~s}$; $\mathrm{LCl}$, Lung Clearance Index, $\mathrm{ROC}$, receiver operating characteristic

starting concentration, in 68 children with $\mathrm{CF}$ ( $\mathrm{n}=44$ with mild disease). In agreement with results from our study, they reported good performance of shortened LCI at $1 / 20$ th of the starting concentration compared with 'standard' LCI. Furthermore, as with the results from our study, Yammine et $a l^{10}$ found that while the earlier LCI end points had good intravisit repeatability, they were less sensitive and specific to the presence of CF. The authors concluded that shortened $\mathrm{N}_{2} \mathrm{MBW}$ to $1 / 20$ th of the starting concentration could offer a more feasible measure for use in clinical practice. In this study we extended these observations to investigate and confirm the utility of shortened ventilation indices in older patients with more advanced disease. Theoretically, in cases of severe flow asynchrony between the best and the least ventilated lung units, the end-tidal concentrations in subsequent breathing cycles can enhance the contribution of the least ventilated units toward the end of the washout where LCI is measured. ${ }^{16}$ This may lead to increased variation in results taken at an earlier end point, such as $1 / 20$ th of the starting concentration. In contrast, LCI from an earlier end point may be more precise, as an end point where the washout curve slope is greater may avoid random breath-by-breath variability that could be observed at a later end point. In this study, $\mathrm{LCI}_{1 / 30}$ and $\mathrm{LCI}_{1 / 20}$ had marginally better sensitivity to the presence of CF (23\% vs $20 \%$ ), compared with $\mathrm{LCI}_{1 / 40}$, even though there was no significant difference in variability (LCI CV\%) between 'standard' LCI $\left(\mathrm{LCI}_{1 / 40}\right)$ and LCI at an earlier end point $\left(\mathrm{LCI}_{1 / 30}, \mathrm{LCI}_{1 / 20}, \mathrm{LCI}_{1 / 10}\right)$. $\mathrm{LCI}_{1 / 30}$ and $\mathrm{LCI}_{1 / 20}$ also had good diagnostic performance and superior sensitivity compared with $\mathrm{FEV}_{1} \%$ predicted. Importantly, these findings indicate that no further additional information was obtained using $\mathrm{LCI}_{1 / 40}$ compared with the shortened versions, $\mathrm{LCI}_{1 / 30}$ and $\mathrm{LCI}_{1 / 20}$.

Test duration for $\mathrm{LCI}_{1 / 30}, \mathrm{LCI}_{1 / 20}$ and $\mathrm{LCI}_{1 / 10}$ was significantly shorter than $\mathrm{LCI}_{1 / 40}$ in people with $\mathrm{CF}$, with an average $5 \%, 9 \%$ and $15 \%$ time saving, respectively. As $\mathrm{LCI}_{1 / 20}$ offers a greater time saving than $\mathrm{LCI}_{1 / 30}$, while maintaining reliability and sensitivity, it provides the most attractive measure and may enhance the feasibility of MBW in the research and clinical setting. The proportion of time saved in this study is smaller than that reported in the study by Yammine et $a l^{10}$ as MBW tests using an exogenous gas such as $\mathrm{SF}_{6}$ require a washin and a washout phase. However, as these results are from a retrospective analysis, the time saving measurement does not take into account the total time saving per testing session. Finishing a test earlier would allow for the second and third test of the triplicate to start sooner, resulting in a larger time saving. Although the washin time is unchanged, any shortening of LCI test duration could be especially useful in younger children where long assessment periods are not feasible, and in patients with advanced disease, where the washin and/or washout periods can be prolonged. The use of MBW equipment using $\mathrm{SF}_{6}$ has been successfully used in multicentre studies and remains popular as it has advantages in terms of tracer gas estimation (measured directly rather than by subtraction as with $\mathrm{N}_{2}$ MBW) avoiding the potential confounding effects of $100 \% \mathrm{O}_{2}$ on breathing pattern. This study is the first to show that MBW using $\mathrm{SF}_{6}$ can be reliably shortened.

Considering potential limitations of shortened MBW tests, one study highlights that advanced analysis of washout curves to determine the relative contribution of convective and acinar airways to ventilation heterogeneity (phase III analysis) usually requires six lung-volume turnovers. ${ }^{17}$ However, recent work suggests that the same information may be obtainable in three lung-volume turnovers ${ }^{18}$ in which case use of $\mathrm{LCI}_{1 / 20}$ would still enable full phase III analysis. Regardless, phase III indices may have limited utility in CF, as demonstrated by Horsley et al. ${ }^{19}$

The retrospective nature of this study is a limitation. However, the study did endeavour to avoid selection bias by use of anonymsied patient data sets as consecutively listed in a database and represents the first exploratory study to report on the clinimetric properties of an earlier end point in $\mathrm{SF}_{6} \mathrm{MBW}$. More data from across the disease severity range in $\mathrm{CF}$ are required to define normal ranges of shortened LCI.

\section{CONCLUSIONS}

$\mathrm{LCI}_{1 / 20}$ is a repeatable and sensitive test with equal diagnostic performance to $\mathrm{LCI}_{1 / 40}$ that is shorter, potentially offering a more feasible research and clinical measure.

Acknowledgements The authors would like to thank the patients and families who participated in this study.

Contributors KO'N recruited patients, collected clinical data, conducted MBW tests and performed lung function assessment; KO'N, DH, JSE and NB analysed data; IB provided statistical analysis support; KO'N, DH, JMB, NB and JSE wrote the paper.

Funding Work funded by HSC Research and Development, Public Health Agency, Northern Ireland and the Medical Research Council through a US-Ireland Partnership Grant.

Competing interests None.

Patient consent Obtained.

Ethics approval This study was approved by the Office for Research Ethics Committees Northern Ireland (ORECNI) (REC reference number: 10/NIR01/41) 
and co-sponsored by BHSCT and QUB (research office reference number: 10067SE-OPMS).

Provenance and peer review Not commissioned; externally peer reviewed.

Open Access This is an Open Access article distributed in accordance with the terms of the Creative Commons Attribution (CC BY 4.0) license, which permits others to distribute, remix, adapt and build upon this work, for commercial use, provided the original work is properly cited. See: http:// creativecommons.org/licenses/by/4.0/

\section{REFERENCES}

1. Gustafsson PM, Aurora P, Lindblad A. Evaluation of ventilation maldistribution as an early indicator of lung disease in children with cystic fibrosis. Eur Respir J 2003;22:972-9.

2. Horsley AR, Gustafsson PM, Macleod KA, et al. Lung clearance index is a sensitive, repeatable and practical measure of airways disease in adults with cystic fibrosis. Thorax 2008;63:135-40.

3. Kent L, Reix P, Innes JA, et al. Lung clearance index: evidence for use in clinical trials in cystic fibrosis. J Cyst Fibros 2014;13:123-38.

4. Davies J, Sheridan H, Bell N, et al. Assessment of clinical response to ivacaftor with lung clearance index in cystic fibrosis patients with a G551D-CFTR mutation and preserved spirometry: a randomised controlled trial. Lancet Respir Med 2013:1:630-8.

5. Subbarao P, Stanojevic S, Brown M, et al. Lung clearance index as an outcome measure for clinical trials in young children with cystic fibrosis. A pilot study using inhaled hypertonic saline. Am J Respir Crit Care Med 2013;188:456-60.

6. Rowan SA, Bradley JM, Bradbury I, et al. Lung clearance index is a repeatable and sensitive indicator of radiological changes in bronchiectasis. Am J Respir Crit Care Med 2014;189:586-92.
7. Macleod KA, Horsley AR, Bell NJ, et al. Ventilation heterogeneity in children with well controlled asthma with normal spirometry indicates residual airways disease. Thorax 2009;64:33-7.

8. Robinson PD, Latzin P, Verbanck $\mathrm{S}$, et al. Consensus statement for inert gas washout measurement using multiple- and single- breath tests. Eur Respir J 2013;41:507-22.

9. Bouhuys $A$, van Lennep $\mathrm{HJ}$. Effect of body posture on gas distribution in the lungs. J Appl Physiol 1962;17:38-42.

10. Yammine S, Singer F, Abbas C, et al. Multiple-breath washout measurements can be significantly shortened in children. Thorax 2013;68:586-7.

11. Nielsen N, Nielsen JG, Horsley AR. Evaluation of the impact of alveolar nitrogen excretion on indices derived from multiple breath nitrogen washout. PLOS ONE 2013;8:e73335.

12. Horsley AR, Davies JC, Gray RD, et al. Changes in physiological, functional and structural markers of cystic fibrosis lung disease with treatment of a pulmonary exacerbation. Thorax 2013;68:532-9.

13. Miller MR, Hankinson J, Brusasco V, et al. Standardisation of spirometry. Eur Respir J 2005;26:319-38.

14. Stanojevic S, Wade A, Stocks J, et al. Reference ranges for spirometry across all ages. Am $J$ Respir Crit Care Med 2008:177:253-60.

15. Bland JM, Altman DG. Statistical methods for assessing agreement between two methods of clinical measurement. Lancet 1986;1:307-10.

16. Verbanck S, Paiva M, Paeps $\mathrm{E}$, et al. Lung clearance index in adult cystic fibrosis patients: the role of convection-dependent lung units. Eur Respir J 2013;42:380-8.

17. Verbanck S, Paiva M. Gas mixing in the airways and airspaces. Compr Physiol 2011;1:809-34.

18. Verbanck S, Paiva M, Schuermans D, et al. Relationships between the lung clearance index and conductive and acinar ventilation heterogeneity. J Appl Physiol 2012;112:782-90.

19. Horsley AR, Macleod KA, Robson AG, et al. Effects of cystic fibrosis lung disease on gas mixing indices derived from alveolar slope analysis. Respir Physiolo Neurobiol 2008;162:197-203. 